\title{
The Influence of Freight Generation Production Characteristics of the Internal - Regional Zone Commodities on Sustainable Freight Transportation Highway Network System
}

\author{
Juang Akbardin ${ }^{1,3^{*}}$, Danang Parikesit ${ }^{2}$, Bambang Riyanto ${ }^{3}$, Agus Taufik Mulyono ${ }^{2}$ \\ ${ }^{1}$ Department of Civil Engineering, Indonesia University of Education, Bandung - Indonesia \\ ${ }^{2}$ Department of Civil Engineering, Gadjah Mada University,Yogyakarta - Indonesia \\ ${ }^{3}$ Department of Civil Engineering, Diponegoro University, Semarang - Indonesia
}

\begin{abstract}
The increasing of commodity freights production in the internal - regional zone is a national development strategy to create interzone consolidation to accelerate the productivity of an internal - regional zone staple commodity. Sustainable freight transportation development requires a strategic direction based on the commodity freights production dominant characteristics in an internal-regional zone. This research has been done to estimate the distribution model and route assignment model of staple alternative commodity. Estimated generation production of commodity freights movement in production zones is influenced by zone demographic variables, infrastructure, and means of transportation. Gravity method is used to estimate the distribution model and route assignment model by calibrating it with Newton-Raphson method. The application and development of the gravity method in the modelling analysis will determine the estimation effect of sustainable freights transportation needed. The computational simulation result is an approach of mathematical model illustration for complex and systematic estimation. Therefore, the modelling results can provide the direction of sustainable highway construction on the highway network system, will determine the effectiveness and efficiency of traffic movement, and distribute the movement.

Keywords: Trip Production, Highway Network System, Freight Transportation
\end{abstract}

$\overline{\text { *Corresponding author: akbardien@upi.edu }}$ 


\section{Introduction}

The need for staple consumption is increasing in accordance with the population growth in a region. Meanwhile, the production of staple commodities declines in general due to the decrease of the staple area production, rice-cultivated paddy fields. Central Java region has a diversity of land that produces alternative staples. The tubers commodity in the Central Java province has sufficient amount of production. Production of tubers and their yields can be used as an alternative staple which has been depending on rice production so far. Production of tubers and their products requires the movement magnitude estimation of the commodity production. The production movement of the tubers commodity and their products evolves in accordance with the demands of the products and the economic laws of supply and demand. The rise of movements resulting from the economic activity of tubers commodity production and its manufactured goods led to an increase in vehicular traffic on the production lines of tuber commodity and its manufactured goods production zones. Production zones generally have highway network systems that are not on the main routes of provincial and state distribution systems. The increase of tuber commodity production, used as alternative staple goods, urges the existing local highway network system to be able to serve the traffic development due to the movement increase, caused by the alternative staple commodity production escalation. So, to support the smooth goods distribution system requires the highway service performance that is able to encourage the increased production of strategic commodities and basic necessities. [2-5]

\section{Gravity Model}

Generating movement is the number of moves generated by a zone of origin (Oi) and the number of moves that are attracted to each destination zone (Dd) included in the study area.

\subsection{Modeling of Freight Transportation}

Gravity model that gives the formula of freight transportation total volume based on the commodity type transported from one place to the other place is as follows (equation 1)

$$
\mathrm{T}_{\mathrm{idk}}=\frac{\mathrm{S}_{\mathrm{ik}} \cdot D_{d k} f_{i d}}{\sum D_{d k} \cdot f_{i d}}
$$

Where:

$\mathrm{T}_{\mathrm{idk}}=$ the number of $\mathrm{k}$ commodity produced in the $\mathrm{i}$ region and sent to the $\mathrm{d}$ region

$\mathrm{S}_{\mathrm{ik}}=$ the total amount of shipments of $\mathrm{k}$ commodity from the $\mathrm{i}$ region

$\mathrm{D}_{\mathrm{dk}}=$ the total amount of demand of $\mathrm{k}$ commodity in $\mathrm{d}$ region

$f_{i d}=$ the friction/ barriers factor $\left(=1 / \mathrm{d}_{\mathrm{id}} \lambda\right)$

$\lambda=$ parameter

This model uses the gravity concept introduced by Newton developed from the gravity law analogy.[1]

$$
F_{i d}=G \cdot \frac{m_{i} \cdot m_{d}}{d_{i d}^{2}}
$$


with $\mathrm{G}$ as the gravitational constant of the movement attraction, as well as distance, time, or cost as an accessibility measurement. Thus, for transportation purposes, the GR model is formulated as: (Equation 3)

$$
T_{i d}=k \cdot \frac{O_{i} \cdot O_{d}}{d_{i d}^{2}}
$$

In which $\mathrm{k}$ is a constant

So, in mathematical equation, GR model can be formulated as below:

$$
T_{\text {id }}=\mathrm{O}_{\mathrm{i}} \cdot \mathrm{D}_{\mathrm{d}} \cdot \mathrm{A}_{\mathrm{i}} \cdot \mathrm{B}_{\mathrm{d}} \cdot \mathrm{f}\left(\mathrm{C}_{\mathrm{id}}\right)
$$

\subsection{Modelling of Transportation based on Traffic Flow}

$\hat{V}$ total flows on certain roads is the sum of the movement between the zones within the study area that use these roads, shown in equation (5).

$$
\hat{V}_{l}=\sum_{i=1}^{N} \sum_{d=1}^{N} T_{i d} \cdot p_{i d}^{l}
$$

Commodity moved between the zones within the study area is represented by a model of transportation demand with Gravity Model Opportunity (GO). In which, $\mathrm{T}_{\text {id }}$ total movement with the $\mathrm{i}$ starting point zone and the $\mathrm{d}$ destination zone for all commodity movements purposes are indicated by equation (6)

$$
T_{i d}=\sum_{k=1}^{K} T_{i d}^{k}
$$

where the commodity that move from i zone to $\mathrm{d}$ zone is shown on equation (7)

$$
T_{i d}^{k}=b_{k} \cdot O_{i}^{k} \cdot D_{d}^{k} \cdot A_{i}^{k} \cdot B_{d}^{k} \cdot f_{i d}^{k}
$$

By substituting equation (7) to equation (5), the basic equation for the transportation demand estimation model with traffic flow data is shown on equation (8) [1]

$$
V_{l}=\sum_{k=1}^{K} \sum_{i=1}^{N} \sum_{d=1}^{N}\left(b_{k} \cdot O_{i}^{k} \cdot D_{d}^{k} \cdot A_{i}^{k} \cdot B_{d}^{k} \cdot f_{i d}^{k} p_{i d}^{l} \cdot\right)
$$

\section{METHODOLOGY}

The modelling approach of sustainable freight transportation which is very complex and extensive is simplified by defining the dominant determined variables.

\subsection{Variable of Generating Movement}

\section{Dependent variables}

$\mathrm{Y} 1=\mathrm{Oi}=$ Generating Movement of Vegetable Commodity 


\section{Independent variables}

$\mathrm{X} 1=$ population,

$\mathrm{X} 2=$ GRDP (Gross Regional Domestic Product),

$\mathrm{X} 3=$ Freights based on tubers commodity and their manufactured products IO,

$\mathrm{X} 4=$ the length of state highways in the Central Java districts or cities,

$\mathrm{X} 5=$ the length of provincial highways in the Central Java districts or cities,

$\mathrm{X} 6=$ the length of local highways in the Central Java districts or cities,

$\mathrm{X} 7=$ highways in good condition in the Central Java districts or cities,

$\mathrm{X} 8=$ highways in moderate condition in the Central Java districts or cities,

X9 = damaged highways in the Central Java districts or cities,

$\mathrm{X} 10=$ severely damaged highways in the Central Java districts or cities,

$\mathrm{X} 11=$ the number of freights vehicles in the Central Java districts or cities,

$\mathrm{X} 12=$ the number of freights vehicles owned by individuals,

$\mathrm{X} 13=$ the number of freights vehicles owned by company

$\mathrm{b}_{0} \quad=\mathrm{a}$ constant

[1-5]

Consumption and Production

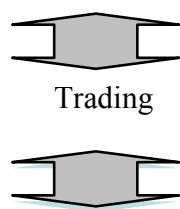

Logistic Services

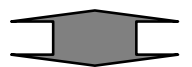

Transportation Services

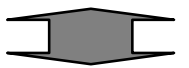

Network System Services
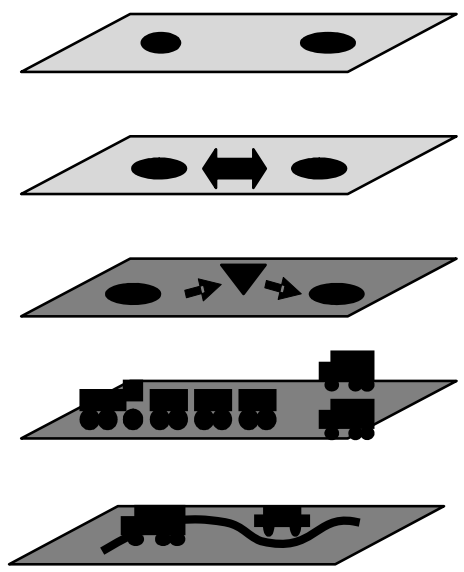

Fig 1. Logical Structure of Freights Transportation 


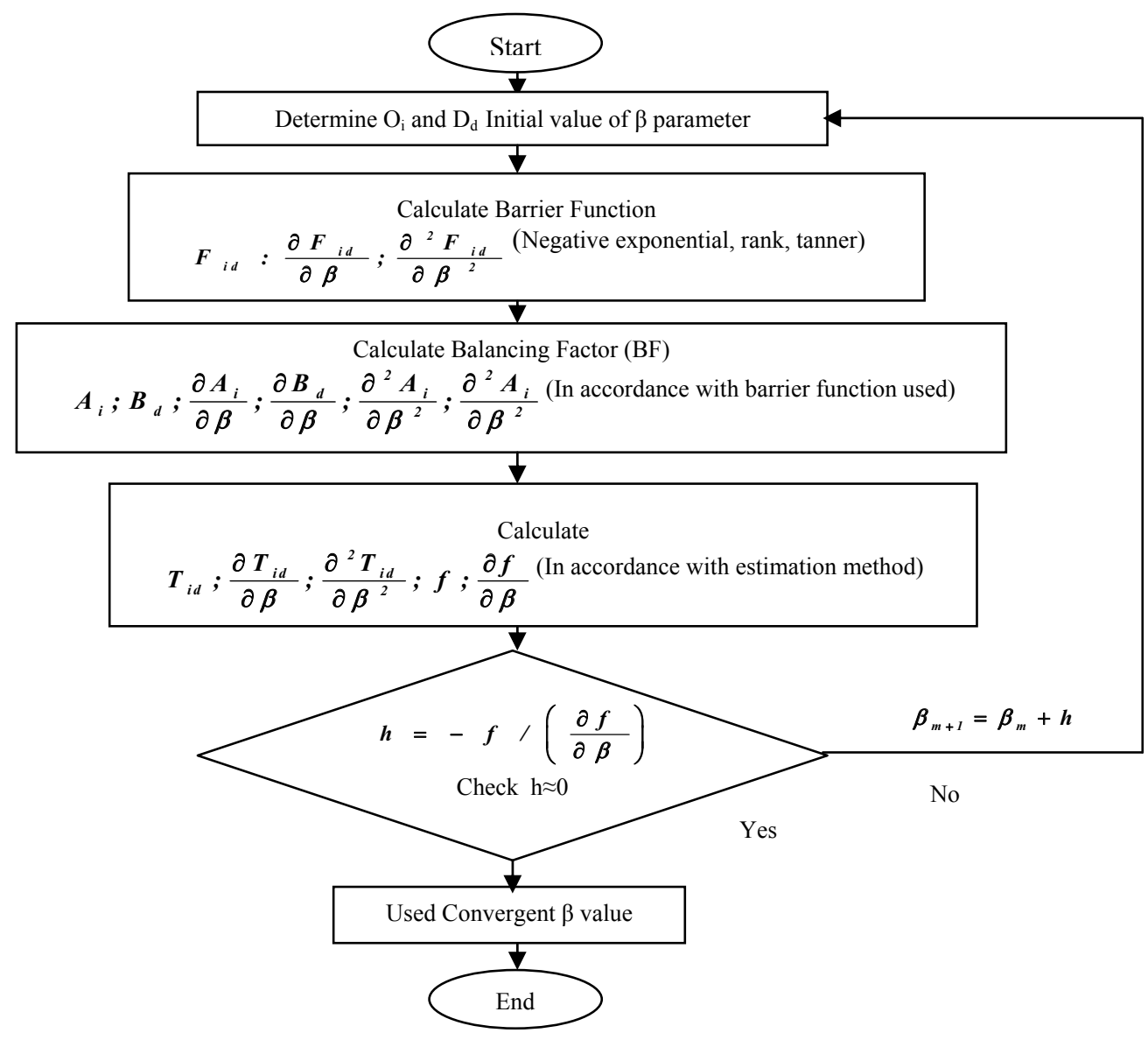

Fig 2. Newton-Rhapson Calibration Method Flow Chart

\section{RESULTS AND DISCUSSIONS}

Generation modelling movements of tubers commodity and their poducts as alternative staples using multiple regression method is shown in equation (9)

Ln Yi $=1,94+0,990 \operatorname{Ln} \mathrm{X} 1+0,194 \operatorname{Ln} \mathrm{X} 2+0,0123$ Ln X3 + 0,0247 Ln X4 + 0,0106 Ln X5 - 0,113 Ln X6+0,0196 Ln X7-0,0249 Ln X8 - 0,0036 Ln X9-0,0451 Ln X10 $-0,108$ Ln X13

The mathematical model equation obtained has been tested with the model significance level where the determination test $\mathrm{R}^{2}=0.87$. Furthermore, the model obtained is simulated based on the data of alternative staple commodity producers' zones with matlab computation method 12 as shown in figure 3. The movement distribution of the alternative staple commodity products using gravity method with each zone model simulation is indicated by Disire Line distribution of movement. [1,4,5] 

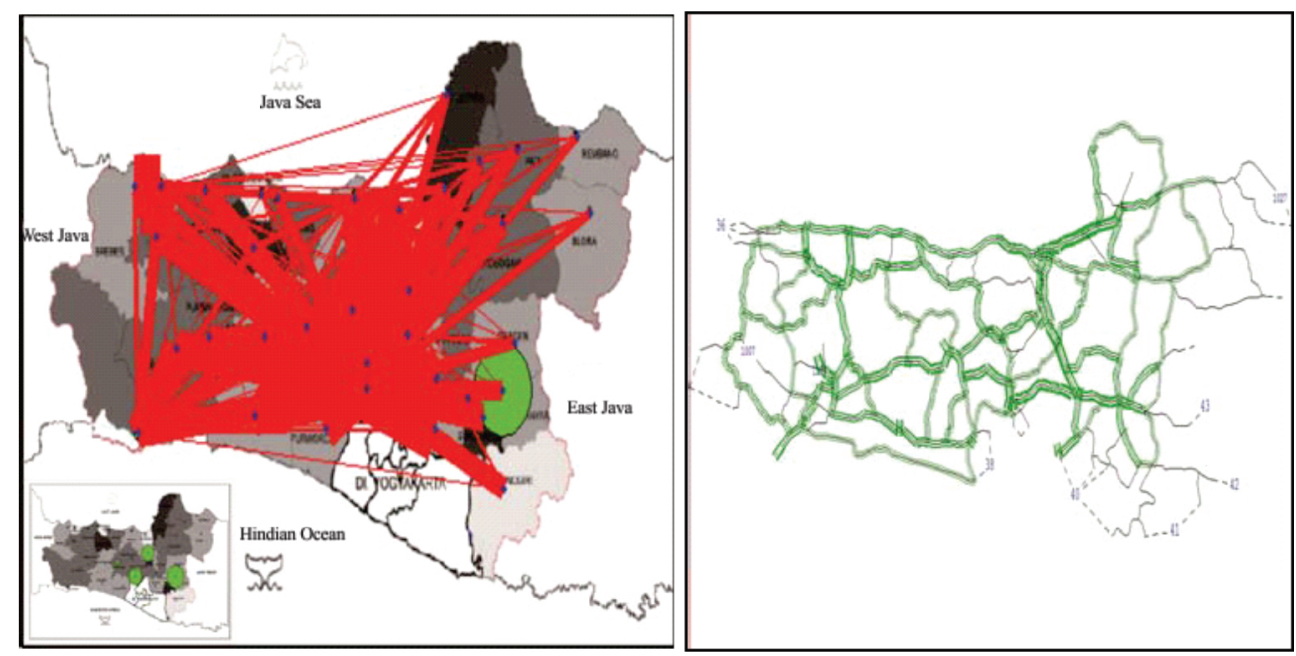

Fig 3. The Simulation of Movement Distribution and Traffic Loading due to alternative staple commodity production according to zone and track path

The data analysis and modeling simulation result shows that the generating movements in alternative staple commodity production zones has adequate significant influence on the highway network system built, particularly in the alternative paths of the main trafficts movement distribution. [1-5].

\section{Conclusion}

The generating movement effects of increased alternative staple commodity production in the regional-internal zone on the highways network system in Central Java shows the saturation degree in the connecting highway network system and the alternative path is increased. It is influenced by the commodity producers zone characteristics that are outside the main distribution highways, and thus it is necessary to expand the highways capacity to support the distribution system on these highways.

\section{References}

1. T. Z. Ofyar. Perencanaan dan Permodelan Transportasi, Second Edition, ITB Bandung(2000)

2. Jin, Y., Williams, I., Shahkarami, M.,. Integrated regional economic and freight logistics modelling: results from a model for the Trans-Pennine Corridor, UK, European Transport Conference (2005)

3. Davydenko, IY, Tavasszy, LA, Meijeren, JJ \& Ivanova, O. Estimation of freight flow and trip generation according to transport purpose in urban and regional logistics networksMETRANS Urban Freight Conference Proceedings (pp. 1-17). Long Beach: METRANS. (2011)

4. V. Holguín, J., M. Jaller, L. Destro, X. Ban, C. Lawson, and H. S. Levinson, Freight Generation, Freight Trip Generation, and Perils of Using Constant Trip Rates, In Transportation Research Record: Journal of the Transportation Research Board, No. 2224, Transportation Research Board of the National Academies, Washington, D. C., pp. 68-81, (2011)

5. Davydenko, Igor Y.; Tavasszy, Lóránt A.; Smeets, Peter S.G.M. Commodity Freight and Trip Generation by Logistics Distribution Centers Based on Sectorial employment Data,91st Annual TRB Meeting, Washington DC (2012). 